\title{
CUERPO (CAMINO-AULA) PARA COMPRENDER-RESIGNIFICAR LA CRISIS DEL HABITAR DESDE LA ESCUCHA DE MÚSICAS POPULARES
}

\author{
BODY (PATH-CLASSROOM) TO UNDERSTAND- \\ RESIGNIFY THE CRISIS OF LIVING FROM LISTENING \\ TO POPULAR MUSIC
}

José Leonardo Ruiz Méndez*

Carlos Alberto Chacón Ramírez**

* Doctor en Educación y Cultura Ambiental de la Universidad Surcolombiana. Docente de la Universidad Surcolombiana. Investigación financiada por la Universidad Surcolombiana.

leonardo1@usco.edu.co 0000-0002-2834-7853

** Doctor en Educación de la Universidad del Valle. Docente de la Universidad del Quindío. Investigación financiada por la Universidad Surcolombiana.

carloschacon@uniquindio. edu.co

0000-0002-5795-2438

Cómo citar este artículo: Ruiz, M. J. L. \& Chacón, R. C. A. (2021). Cuerpo (caminoaula) para comprenderresignificar la crisis del habitar desde la escucha de músicas populares. Revista PACA 11, pp. 157-173.
Resumen: Esta investigación es canto de cuerpo sintiente, manifestación de sentires presentes en la escucha de las músicas populares de los cuerposjóvenes-universitarios; exposición de una crisis del habitar que nos des-cubre en medio de la trama, en el aula de la vida.

Es construcción de una propuesta que, desde el sentir pretende des-cifrar la relación cotidiana entre cuerpo y habitar reivindicando la vida sensible como hecho fundante de ser humano. En este sentido comprende que, al construirse mundo simbólico desde las palabras y la relación con las cosas, se define lo estético y lo poético del habitar entramado en las urdimbres de la naturaleza ecosistémica, de la naturaleza cultural y de la naturaleza afectiva.

La escucha de las músicas populares revelada en forma de cuerpos embelesados, despechados y sometidos que cantan sin saberlo la crisis civilizatoria, devela la crisis profunda, la del sentir, la que pide dejar las cifras, los porcentajes, las estadísticas, para escuchar el cuerpo y así volver a la tierra natal. Cuerpo donde reside la crisis de la totalidad de los símbolos (Noguera, 2012, p. 10), crisis de una escucha que evidencia un habitar relacionado con las lógicas del capital, del desarrollo, del progreso. 
Métodoestésis-Paidagoestésis, encuentro con el sentir como camino y aula de la vida.

Palabras clave: ambientalización-de-la-educación, habitar, músicas-populares, escucha, métodoestésis-paidagoestésis, cuerpo, sentir, crisis civilizatoria.

Abstract: This research is a song of the sentient body, a manifestation of feelings present in listening to the popular music of the university-youth-bodies; exposition of a crisis of living that uncovers us in the middle of the plot, in the classroom of life.

It is the construction of a proposal that, from the point of view, tries to decipher the daily relationship between the body and inhabit, claiming the sensitive life as the founding fact of being human. In this sense, he understands that, when the symbolic world is constructed from words and the relationship with things, the aesthetic and poetic aspects of living are defined, woven into the warps of the ecosystemic nature, of the cultural nature and of the affective nature.

Listening to popular music revealed in the form of enraptured, disgusted and subdued bodies that sing unknowingly the civilizational crisis, reveals the deep crisis, that of feeling, the one that asks to leave the figures, the percentages, the statistics, to listen to the body and thus return to the homeland. Body where the crisis of the totality of symbols resides (Noguera, 2012, p. 10), a crisis of listening that shows a dwelling related to the logics of capital, development, and progress.

Method-estésis-Paidagoestésis, encounter with feeling as the path and classroom of life.

Keywords: environmentalization-of-education, living, popular-music, listening, method-estésis-paidagoestésis, body, feeling, civilizational crisis.

\section{Introducción-Obertura}

Cuerpo de la obra como una propuesta teórico-metodológica que surge en el Programa de Doctorado en Educación y Cultura Ambiental de la Universidad Surcolombiana. Expone una ruta investigativa, de carácter cualitativo que recorre contornos filosóficos, epistémicos y Métodoestésicos-Paidagoestésicos, oxigenados por los aportes de la Ambientalización de la Educación (Noguera, 2004). Asume el propósito de desfamiliarizar los procesos culturales que forjan la relación simbólica entre la escucha de las músicas populares y la crisis del habitar, para construir una propuesta Métodoestésica-Paidagoestésica. 
Para alcanzar el fin enunciado, se delimitan dos in-tensiones de investigación: en la primera, se estudia la crisis del habitar desde la escucha de las músicas populares, teniendo en cuenta las letras de las canciones seleccionadas para indagar el lenguaje utilizado en relación al mito, el cuerpo y el habitar. En la segunda, a partir de la vivencia de la crisis mencionada, se diseña una Métodoestésis-Paidagoestésis (Chacón, 2018) (Noguera, 2017 y 2018) que desde músicas-cuerpos-mundo-dela-vida-cotidiana, interprete, comprenda y devele, lo estético de los consumos culturales y su relación con lo ambiental como un camino alternativo del sentir, lo sensible, la vida sensible, lo sintiente, lo sentido y los sentidos, para investigar en una ambientalización de la educación desde el pensamiento ambiental sur.

Esta crisis de la que hablamos, se puede evidenciar en diferentes fuentes. Una de ellas es la música. Los relatos que estamos buscando, asociados a la crisis del habitar, los podemos encontrar en las letras de las canciones de la música popular, debido a que ésta, según González (2001) es mediatizada (industrializada), masiva (globalizada) y modernizante (expresión del presente), lo cual nos ubica en el momento histórico que queremos estudiar. Además, porque la música "...da forma a la memoria colectiva, la de organizar nuestro sentido del tiempo" (Frith, 1987, p. 9), "...ha constituido una vía fundamental para aprender a entendernos como sujetos históricos, con identidad étnica, de clase y de género" (Frith, 1987, p. 11).

Para poder lograrlo, debemos tener presente que "el habitar, el morar implica el Ethós de la tierra como morada del hombre. La tierra es la que permite un morar poético. Pero ella, la ética, no está solamente en lo humano. Ella está ya en la tierra y le dice al hombre cómo morar. La libertad del hombre no consiste en obrar como él quiera en sus formas de habitar. Consiste en saber y ese saber está en la naturaleza. Consiste en dejarse en el habitar" (Noguera, 2012, p. 79); también, comprender el "Sentido del habitar, como nicho de las representaciones, de los símbolos, del lenguaje, del espacio de los sucesos de la vida" (Chacón, 2011, p. 198).

Este proceso de construcción simbólica ha conllevado el despliegue de estrategias de adaptación y transformación de la naturaleza, por esta razón, el estudio de dichos procesos culturales debe ser el objeto de estudio de lo ambiental, pues "toda cultura organiza una secreta 
red de símbolos que son, en última instancia, los que desencadenan los comportamientos individuales y sociales. Sin entender este mundo simbólico es muy difícil comprender la manera como el hombre actúa sobre la naturaleza" (Ángel-Maya, 2013, p. 90).

El estudio de la relación cultura-naturaleza se ha aplicado desde enfoques de estudio que han mostrado un distanciamiento de la condición estética del ser humano, donde lo estético se ha entendido "...no sólo como lo artístico, que está sin duda dentro de lo estético, sino también como aquello que me permite comprender al mundo y al ser humano desde la diversidad de formas de ser ellos mismos. La sensibilidad y el entendimiento dan forma al mundo; dan sentido a lo existente como existente. $Y$ este sentido es lo que me permite reconocer la alteridad, la diferencia" (Noguera, 2000, p. 106). En consecuencia, sin vincular a la educación el estudio de los procesos de construcción simbólica que sustentan los juegos de la cultura (Mandoki, 2006), sería difícil alcanzar soluciones definitivas a los problemas ambientales.

Teniendo en cuenta lo anterior, esta investigación acoge la propuesta de la Dra. Ana Patricia Noguera, en relación a la necesidad de ambientalizar la educación, entendida como:

\begin{abstract}
"Imágenes e imaginarios de naturaleza y de cultura, que hemos construido y que compartimos dentro de la escuela. Por ello la resignificación de las mismas palabras "naturaleza», "sociedad», "cultura», "medio ambiente», nos exige un cambio de actitud (una nueva ética) en los procesos pedagógicos de apropiación de los discursos que soportan dichos conceptos. La ambientalización (que es de alguna manera poetización y estetización) de las hablas tanto científicas como cotidianas, se transforma inmediatamente en ambientalización de las acciones y de las relaciones". (Noguera, 2004, p. 65).
\end{abstract}

\title{
Metodología: Estésis como construcción investigativa
}

Despojo de la razón, desfamiliarización de un pensamiento centrado en el dato, la estadística y los indicadores. Manera de ser investigadorotro, sin recetas ni esquemas preconcebidos; investigador-otro que se arriesga, que da su mismo cuerpo a la resignificación. Un a-método que incluye un viaje de ida y regreso con transformación: "si el camino es una trayectoria en espiral, el método ahora consciente de sí descubre y nos descubre distintos" (Morín, Ciurana y Motta, 2002, p. 19). 
Para encontrar los vestigios de esta crisis del habitar que nos agobia, consideramos la estésis como camino, es decir, como "vida sensible" (Coccia, 2011) que implica "maneras de crear, transformar, estar, sentir" (Noguera, 2012); como expresión de "sensibilidad o condición de abertura o permeabilidad al contexto..." (Mandoki, 2006, p. 11), para el vislumbramiento de la escucha en producción de imágenes sonoras, pues "sólo a través de lo sensible - a través de las imágenes- penetramos en las cosas y en los otros, podemos vivir en ellos, ejercer influencia sobre el mundo y sobre el resto de los vivientes" (Coccia, 2011, p. 65).

De igual manera, consideramos la estésis como cuerpo-aula, es decir como "...lugar del acontecimiento, cuerpo simbólico en espaciamiento, en el espacio-espaciado con sentidos de la tierra" (Chacón, 2011, p. 9); como lugar para la interpretación de "...las huellas dejadas por los hábitos del ser en la superficie habitada" (Pineda, 2017, p. 78); como lugar para el encuentro del sentir de los cuerpos-tierra (Noguera, 2012), dibujado en las letras de las canciones de las músicas populares; como lugar para la escucha de "lo ya sentido" (Perniola, 2008), entendido como “...intimación, como orden dada a todo el mundo de reafirmar lo que ha experimentado y aceptado, y cuya única legitimidad reside en este acuerdo general y anónimo: la libre conversación entre los hombres" (Perniola, 2008, p. 30); como lugar para la comprensión de que "...nosotros comportamos, envolvemos, implicamos... un Espacio, y no un espacio cualquiera, sino el espacio perfectamente cualificado, el contorno distinguido, y distinguible que constituye exacta y precisamente nuestro territorium y que nos determina a ser exactamente el individuo que somos" (Pardo, 1991, p. 63); como lugar donde habita el mundo simbólico, que es "toda la rica experiencia del hombre, que recoge en el lenguaje escrito, oral o artístico, las múltiples facetas de experiencia cultural..."(Ángel-Maya, 2013, p. 109).

Esta Métodoestésis (Noguera) - Paidagoestésis (Chacón) que es el camino del sentir $y$, en consecuencia, el cuerpo como camino en el espíritu de la compañía, es decir el maestro que acompaña en sentidos de la estésis, fue constituyéndose en el dialogo con los cuerpos-jóvenesuniversitarios de la Universidad Surcolombiana, sede Neiva, a través de las manifestaciones de la relación cuerpo, mito y habitar.

Dos momentos consolidan la recolección de la información: la promulgación e interpretación de los relatos, y la construcción, des- 
ciframiento y re-significación de la banda sonora. El primer momento, se efectúa en varios cursos de diferentes Facultades de la Universidad Surcolombiana. Con un total de ciento cincuenta y tres cuerpos-jóvenesuniversitarios, se propuso el abordaje de enunciados que motivaran la conversación. El segundo momento, implementado en el curso institucional de Medio Ambiente, expuso la construcción hermenéutica de la Banda Sonora a partir de las músicas populares más escuchadas por los cuarenta y cinco cuerpos-jóvenes-universitarios matriculados. Luego, se identificaron tendencias, como propensiones encontradas en las conversaciones con los cuerpos-jóvenes-universitarios.

\section{Referentes teóricos: Rizomas simbólicos}

Una planta rizomática se expande desde cualquier punto. Sus brotes le permiten difundirse sin límite hacia cualquier lado. No existe para la planta rizomática, una rama principal, no tiene un plan determinado, se construye sobre las necesidades de existencia.

Así, surgen los brotes de este estudio, los cuales evidencian lo mencionado por Deleuze y Guattari (2004, p. 26), en relación a que “...una de las características más importantes del rizoma, quizá sea la de tener siempre múltiples entradas...".

Emanuele Coccia (2011, p. 10) ha propuesto el concepto "Vida Sensible" argumentando que ésta "...no es sólo lo que la sensación despierta en nosotros. Es el modo en que nos damos al mundo, la forma en la que somos en el mundo y, a la vez, el medio en el que el mundo se hace cognoscible, factible y vivible para nosotros. Sólo en la vida sensible se da el mundo, y sólo como vida sensible somos en el mundo".

La analogía del concepto cuerpo-tierra que buscamos, es construida por Noguera (2012, p. 24) con los aportes de Leroi Gourham (1971) y de Guattari (1996): "La vida... es la emergencia como trama, en las urdimbres de las tres poéticas: las urdimbres de la naturaleza ecosistémica, las urdimbres de la naturaleza cultural y las urdimbres de la naturaleza afectiva...Cuerpo-tierra: es Cuerpo-mundo-de-la-vida-simbólico-bióticoafectivo. Es afección que reúne los intentos por devenir multiplicidadcuerpo, cuerpo-múltiple; cuerpo configurado en las múltiples maneras de la piel". 
El concepto cuerpo-tierra alude a cuerpo-símbolo, es decir, a la cultura como entramado de símbolos "el proceso de moldear el mundo de la vida simbólico-biótico, de transformarlo, de darle sentidos diferentes, de potenciarlo con nuevas formas, de complejizarlo" (Noguera, 2000, p. 37); "el conjunto de la formación social que incluye las herramientas físicas (técnica), las formas de organización social y las manifestaciones simbólicas" (Ángel-Maya, 2013, p. 80). Como consecuencia, "la Palabra Cultura...indica que la tierra, el humus profundo del hombre, ha sido roturado" (Artaud, 1984 p. 131 cit. por Noguera, 2017, p. 44).

Estas explicaciones, fortalecen el segundo brote: Símbolo-cultura, pues las formas expresivas en conjugación, permiten construir el aura comunicativa del ser humano en forma de surcos que dirimen el acontecercotidiano-humano: cultura- arada-cultivada-cosechada.

La vinculación del espacio-territorio-Geopoética, configuran el tercer brote de estudio, con el cual se define la importancia de considerar la tierra como un lienzo donde se dibujan los aconteceres humanos.

Para continuar con el cuarto eje de estudio, es necesario explorar la relación entre espacios y hábitos, la cual es explicada por Pardo (1991) de la siguiente manera:

\footnotetext{
"Los espacios no son hechos por sus habitantes ni inventados por sus individuos (iellos son individuos") están hechos de hábitos y son los hábitos quienes hacen al habitante o, mejor aún, 'habitúan', 'hacen habitante' (los estetogramas son rasgos individuantes). Tales hábitos, por su parte, son la huella dejada en el Espacio de una intensidad que ha herido al ser, el signo del acontecimiento (el paso del rio por la montaña; así en las montañas tajadas -talladas- por las aguas pueden observarse las huellas secas de la fuerza liquida que ha esculpido la physis) que no es presente ni puede serlo (sólo se entrevé en el pasado - mítico, remoto- que el rito - el dibujo 'sobre' la tierra - rememora y celebra, o en el futuro- igualmente extemporáneo que el mismo rito anuncia, anticipa)" (Pardo, 1991, p. 33).
}

Es decir, en el trasegar simbólico, dejamos los signos del acontecimiento, que no es otro que el hábito. En tal sentido, el hábito se relaciona con el comportamiento, porque "...nos comportamos: esto es, llevamos con nosotros, comportamos, transportamos y soportamos las fuerzas, los estímulos, los paisajes que nos determinan y constituyen, los Espacios inscritos en nuestra exterioridad". Se congregan así las palabras hábitoscomportamientos, para conformar el cuarto y brote de estudio. 
El brote Vida-Sensible-cuerpo-tierra del Pensamiento EstéticoAmbiental es la Métodoestésis-Paidagoestésis, porque es: cuerpo-mundode-la-vida-biótico-simbólico-afectivo. Es la manera como un grupo de personas se da al mundo en medio de la crisis. Es cuerpo afectado que quiere ser con lo-los demás, para transfigurar el mundo. En tal sentido, Vida-Sensible-Cuerpo-Tierra se hace presente en el acontecer por la Métodoestésis-Paidagoestésis como privilegio de la experiencia de la vida sentida que se retroalimenta en cada acción con lo-los demás.

El brote espacio-territorio-Geopoética del pensamiento AmbientalSur es la Ambientalización de la educación porque es:

\begin{abstract}
“...Enigma que emerge de los aportes de las Teorías del Caos y de la Complejidad, de las Teorías de los Imaginarios Sociales y Simbólicos, de la propuesta Rizoma, de la metáfora de la Trama y la Urdimbre, de la propuesta de Geografías del Contacto, de los conceptos-imágenes cuerpomundo-de-la-vida-simbólico-biótico, de la Complejidad Ambiental, de la propuesta Ecosistema-Cultura, que al mismo tiempo ha sido la fundante de la Ambientalización de la educación" (Noguera, 2012, p. 47).
\end{abstract}

El misterio de la presencia humana sobre la tierra como muestra del espacio comportado, territorio definido, que se encarna GeopoéticaPaideia.

La propuesta Métodoestésis-Paidagoestésica es símbolo-cultura porque implica:

"una transformación profunda de los símbolos de las cultura moderna, que abarca una trasformación radical de la economía, de las maneras como se construye el conocimiento, de la educación, de las prácticas industriales, de la vida cotidiana, del lenguaje, de los mitos e imaginarios" (Noguera, 2012, p. 16).

Presencia de cambio sobretodo en la educación, como generadora de transformaciones que motivan la renovación de prácticas económicas que trasciendan la experiencia del sentir más allá de una posibilidad para hacer riqueza al estilo capitalista.

La propuesta estético-ambiental-complejo, es estética porque:

"...exige la modificación de las maneras del habitar humano moderno que son entramado simbólico (Cfr. Ángel-Maya, 2000); ética porque está 
preguntándole al habitar humano moderno sobre su propio ser como ethós, es decir, como expansión de su propio cuerpo, como emergencia de sí mismo en sentido spinozista, y epistémica porque interroga la escisión que es clave en la configuración del sujeto-yo-razón (ego-cogito) de poder y de dominio, sobre la naturaleza-objeto (res extensa)" (Noguera, 2012, p. 16).

Donde lo estético se entiende como: "expansiones-contorsionesacciones-reacciones de la piel, entendida ésta como trama de la vida" (Noguera, 2012, p. 70); y “... no sólo como lo artístico, que está sin duda dentro de lo estético, sino también como aquello que me permite comprender al mundo y al ser humano desde la diversidad de formas de ser ellos mismos. La sensibilidad y el entendimiento dan forma al mundo; dan sentido a lo existente como existente. $Y$ este sentido es lo que me permite reconocer la alteridad, la diferencia" (Noguera, 2000, p. 106).

La propuesta Métodoestésica-Paidagoestésica es ambiental porque "lo ambiental no es un objeto, sino una densa trama de relaciones, emergente a su vez de las dinámicas de la vida en su forma eco-biopsico-social" (Noguera, 2012, p. 49); es "la relación compleja y en red entre los ecosistemas y las culturas" (Noguera, 2000, p. 103); es "Pensar ambientalmente, dejarse habitar por el ser (pensar) es pensar a partir del otro y de lo otro" (Noguera, 2012, p. 86); lo ambiental como bucle-redtrama-de-vida (Noguera, 2007).

En lo Métodoestésico-Paidagoestésico, los hábitos-comportamientos se relacionan con el consumo ya que éste según García Canclini “...es el concepto clave para explicar la vida cotidiana, desde el cual podemos entender los hábitos que organizan el comportamiento de diferentes sectores, sus mecanismos de adhesión a la cultura hegemónica o distinción grupal, de subordinación o resistencia" (1984, p. 73). Argumento claro que evidencia la conexión entre lo cultural y lo comercial que sin duda alguna está relacionado con la satisfacción de las necesidades, así como de las condiciones de vida de los seres humanos.

Por su parte, Jesús Martín Barbero aborda el concepto de consumo cultural desde los procesos de comunicación que ejercen las sociedades de fin de siglo, a partir del cuestionamiento de racionalidades económicas, políticas y simbólicas que regulan las formas de consumo y las modalidades de la recepción los cuales compiten por la apropiación del producto social 
(2006). En sus aportes, el autor en mención considera que el espacio de la reflexión sobre el consumo, es el espacio de las prácticas cotidianas en tanto lugar de interiorización muda de la desigualdad social, en relación con el propio cuerpo, el uso del tiempo, el hábitat, y la conciencia de lo posible en cada vida, de lo alcanzable e inalcanzable.

\section{Resultados}

Por el diseño de la presente investigación, este apartado se presenta incluido en la siguiente sección.

\section{Discusión (Improvisación en vivo)}

A continuación, se presentan cada uno de los motivos a la manera de improvisaciones musicales, que son brotes sonoros de los rizomas construidos, con deseos de ser escuchados, dispuestos a seguir expandiéndose con sus raicillas melódicas, líricas y texturales para generar nuevos brotes territoriales con deseo de desterritorializarse en múltiples líneas de fuga.

Improvisación 1: Relatos que intentan explicar la existencia.

Mundo-de-la-vida-cotidiana que dice de la relación entre cuerpo, mito y habitar. Mundo simbólico entramado en forma de relatos que nos hablan al oído como necesidad por encontrar desde la escucha explicaciones acerca de la existencia.

La felicidad como mito es una historia que se ha desplegado como creencia. ¿Relato que libera al cuerpo humano de su responsabilidad con el habitar? La búsqueda de la felicidad conecta con el mito artúrico del Santo Grial. Ir al encuentro de algo, requiere recorrer un camino literalmente comprendido, pues, es una exploración territorial que pretende encontrar el "propio camino" sin letreros ni sendas marcadas.

El progreso ha sido construido como relato que sustenta la modernidad. Configura un humano que ha creído ser sobrenatural, capaz de incidir en lo-los-demás. Incapaz de verse así mismo. 
Eufonías que son concordancias, y disonancias que son tensiones, hablan de palabras, imágenes, símbolos que acompañan y dan movimiento al mundo-de-la-vida-cotidiana definiendo su relación con el habitar. Cuerpos como melodías que se mueven en su propio trasegar, mitos como escalas musicales por donde circulan los cantos individuales que devienen colectivos.

Improvisación 2: Palabras cantadas como música del mundo-de-lavida-cotidiana.

El mundo-de-la-vida-cotidiana (Noguera, 2000) es el cuerpo mismo en su diario trasegar. Mundo como cuerpo, cuerpo como mundo simbólico en forma de palabra cantada que desvela el habitar.

En esta búsqueda, el camino se considera tendencia abrazadora que abriga los devenires vida-muerte, amor-desamor, familia-soledad, diosuniverso, felicidad, cuerpo, dinero y cosas; todos, configuran un cuerpo que se canta en forma de mundo-de-la-vida-cotidiana.

Estudio de las palabras cantadas que se repiten con la expectativa de seguir la huella del habitar. Camino como tendencia abrazadora que se hace trama al entramarse. Continuo uso de palabras como camino, caminos, calle, caminar, caminarlos, caminaba, anda, andarlos, anduve, rodando, marcharse, nadar; evidencias de la alegoría del cuerpo como camino, del camino como forma del mundo-de-la-vida-cotidiana.

En el siguiente link, se encuentra una selección de fragmentos de canciones que abordan la tendencia referente al camino https:// soundcloud.com/leo-ruiz-626613744/elcamino

Eufonías y disonancias de la palabra cantada, como cuerpo en clave simbólica que se construye entre consonancias y tensiones, pues dice cómo es su habitar. Cuerpos líricos que encarnan las imágenes que los constituyen. Canto que requiere del acompañamiento orquestal para su re-presentación. Canto sobre amplificado que ha ocultado la orquesta. Canto que es cuerpo, orquesta que es naturaleza. Cuerpo-cantante, orquesta-naturaleza. 
En el siguiente link se presentan fragmentos de canciones estudiadas que abordan palabras cantadas como música del mundo-de-la-vidacotidiana https://soundcloud.com/leo-ruiz-626613744/mundo-de-lavida-cotidiana

Improvisación 3: Cosas que constituyen mundo-de-la-vida-cotidiana.

Necesidad de las cosas para ser. Cosas que son timbres e instrumentos invitados al concierto. Trascurrir textural polifónico en la relación con las cosas como consecuencia de la modernidad. Cosas como presencias, imágenes cargadas de símbolos, que ayudan a construir historias. Comercio sensible que deviene en forma de fines y no de medios. Es a través de las cosas que se deviene mundo-de-la-vida-cotidiana, sin embargo, el exceso de esta relación ha configurado un habitar recargado que se convierte en símbolo de ambición y despilfarro. Cosas como nexos entre cuerpos humanos que quedan expuestos en la escena del habitar. Cosas que son memoria, extensión del cuerpo, diversidad de significados según los pactos personales. Cosas que revelan lo estético del mundo-dela-vida-cotidiana.

Improvisación 4: Las Tres Urdimbres y la crisis del habitar desde mi banda sonora.

La crisis del habitar se comprende como consecuencia de la separación entre el mundo de la naturaleza y el mundo de la cultura, así, la trasgresión del ethos de la tierra deja en todos los cuerpos las huellas del habitar humano.

Las urdimbres de la naturaleza ecosistémica desde las músicas populares, se convierten en posibilidades metafóricas que manifiestan estéticamente la capacidad de construir símbolos, con lo cual, se garantiza una especie de conexión entre los cuerpos humanos.

Las urdimbres de la naturaleza cultural comprenden el habitarse así mismo, en comunidad y en correspondencia con la tierra. La historia que se funda desde las músicas populares, canta la necesidad del encuentro de los cuerpos. De esta manera, se concibe un mito-fundante que configura una existencia basada en la necesidad de compartir la vida con alguien, especialmente con una mujer. 
Las urdimbres de la naturaleza afectiva se interpretan como las maneras en que el símbolo constituye afección para el cuerpo. Las lógicas capitalistas comercializan las posibilidades estésicas a través de las cuales conquista el cuerpo humano con fines económicos. Así, queda develada la necesidad de comprender esta interacción de los cuerpos como una somapoética (huellas dejadas).

A partir de la creación del cuerpo como mito-universo se define la manifestación del habitar. En consecuencia, la necesidad de piel, enfocada en la seducción y en el encuentro sexual, define tres tendencias: cuerpo embelesado (abrazados, acostados), deslumbrado de sí mismo como especie, maravillado en las estancias del placer; cuerpo defraudado o despechado (espalda contra espalda), que se vuelven errantes y sufrientes; $y$, cuerpos sometidos (cabizbajos), aquietados por el control político de las instituciones.

En el siguiente link, se encuentra una selección de fragmentos de canciones que abordan la tendencia correspondiente a cuerpos embelesados https://soundcloud.com/leo-ruiz-626613744/cuerpos-embelesados

La crisis del habitar evidencia unos cuerpos alejados del sentido de vida como un todo, olvidando que somos únicamente en relación con la tierra. Despilfarro estésico que promueve un estado de libertad que ha llevado a afectarnos y afectar nuestro propio habitar.

Crisis del habitar que es la misma crisis de los símbolos, crisis civilizatoria, crisis de lo estético y crisis de lo ambiental. Crisis de lo estético al comprender que las músicas populares son ajuar simbólico que escogemos para dar forma al mundo-de-la-vida-cotidiana (Noguera). Que revela el comercio de lo sensible a partir de un cuerpo imaginario constituido en forma de deseo, el lamento de un cuerpo que sufre la agonía del desamor, $y$, el dolor de un cuerpo lastimado por el sometimiento que se traduce en desesperanza. Crisis de lo estético que desligitima otras manifestaciones que también fundan vida desde lo estésico y lo estético.

Esta crisis del habitar y crisis de lo estético, recae en una crisis ambiental que se devela en los deseos de un cuerpo que no pertenece a ningún nicho del ecosistema (Ángel-Maya), por lo cual todos los intercambios simbólicos que sustentan la cultura, están por fuera de los intercambios energéticos de los ecosistemas. 
Improvisación 5: Necesidad de una Métodoestésis-Paidagoestésis.

En el habitar-escolar resuena la necesidad de acoger una educación rizomática que alcance el sueño de una ambientalización de la educación. Que dé cobijo a un a-método, que no significa en ningún momento, ausencia de método, sino otro método, uno que sea construido desde la estésis personal. Uno que escuche el pálpito, la intuición y el deseo investigativo, que lo lleve a encontrar-se en medio de los brotes de territorialidad que luego se desmarquen en desterritorialidades y en líneas de fuga. Uno que le permita comprender-se en el habitar, uno que le devele lo ambiental.

Improvisación 6: Un encontrarse a sí mismo.

Investigación que es símbolo de una compañía permanente por parte del director de tesis. Estudio dedicado y disciplinado que inicia de la incertidumbre y llega a un deseo de continuar buscando. Revelación de un modo especial de investigar. Que no es explícitamente expuesto, es simplemente un dejar ser. Compañía oportuna en momentos de duda y desazón. Encuentro con multitud de voces que en resonancia llegan llamando la atención, escucha, escucha... son los autores consultados que reposan en el sentir universal.

\section{Conclusiones (Coda)}

Desde una Método-estésis Paidago-estésis, promulgamos el siguiente manifiesto:

Necesitamos una educación...

Que defienda el derecho a reconocerse desde el sentir y no desde la razón. Comprometida con la necesidad de volver a la tierra, reconociendo su ethos y descifrando la somapoética y la geopoética del habitar.

Que reconozca el cuerpo como camino, el cuerpo como aula, el cuerpo en necesidad de transformación. Que reconozca el cuerpo como lugar de creación. Que entienda la biodiversidad como manifestación de la multitud de cuerpos vivos, aliados todos de los seres humanos. 
Que entienda, que en el comercio de lo sensible, que es el mismo de las imágenes, se define la influencia del consumo en relación con el habitar y con lo ambiental. Que comprenda que todo consumo es cultural, si se tiene en cuenta que los intercambios simbólicos que hacemos desde las palabras y las cosas, constituyen vida sensible que se vuelve cultura.

Que comprenda que el llamado "Desarrollo" nos ha llevado a la catástrofe ambiental. Que muestre la comercialización del cuerpo que hace el capitalismo y todo el despilfarro estésico que participa en estas lógicas.

Que encuentre en el relato, el lenguaje del cuerpo afectado por la crisis del habitar.

Que manifieste abiertamente que el cuerpo no debe estar en relación con indicadores, cifras, estadísticas, porcentajes ni números que lo aten a esquemas racionalistas, sino con los relatos que lo constituyen para luego promover su develamiento.

Que promueva el construir como un pensar que deviene del sentir.

Que se entrame en las urdimbres de la naturaleza ecosistémica, las urdimbres de la naturaleza cultural y las urdimbres de la naturaleza afectiva.

Que cuestione las músicas populares por ser lugar de comercialización de los cuerpos, al pretender el encuentro de los cuerpos en situación de embeleso, despecho y sometimiento.

Que promueva una escucha ambientalizada que sintonice los símbolos de la crisis del habitar para luego de-construirlos y resonarlos.

Que encuentre en el develamiento del mito fundante la oportunidad para que el cuerpo comprenda la crisis del habitar y se transforme.

Que promueva que el habitar es ligadura del sentir y que el habitar es entramado del construir. Así mismo, que el construir desde el sentir es lo poético y que lo estético y lo poético constituyen el construir que es el pensar. 
CUERPo (CAMINO-AULA) PARA COMPRENDER-RESIGNIFICAR LA CRISIS DEL HABITAR DESDE LA ESCUCHA...

\section{Bios-bibliografía}

Ángel-Maya, A. (2013). El Reto de la Vida. Ecosistema y cultura, una introducción al estudio del medio ambiente. Segunda edición. https://www.rds.org.co/ es/recursos/el-reto-de-la-vida-ecosistemas-y-cultura-una-introduccion-alestudio-del-medio-ambiente

Barbero, J. M. (2006). Recepción de Medio y Consumo Cultural: Travesías. En Sunkel, G. (2006). El Consumo Cultural en América Latina.

Chacón, C. A. (2011). Pensamiento Ambiental del Maestro: Ethos-Cuerpo en clave de BioGeo-Poéticas del Habitar. Universidad del Valle.

Chacón, C. A. (2018). Biodiversidad de la vida: riesgos en la aldea global. En Noguera, A.P. (2018). Pensamiento Ambiental en la era planetaria. Biopoder, bioética y biodiversidad. Una interpretación de los desafíos simbólicobióticos en la aldea global. Universidad Nacional de Colombia.

Coccia, E. (2011). La Vida Sensible. Grupal Logistical y Distribución.

Deleuze, G., Guattari, F. (2004). Mil Mesetas. Capitalismo y Esquizofrenia.

Frith, S. (1987). Hacia una estética de la música popular. https://sociologiacultura. pbworks.com/f/Frith.pdf

García Canclini. (1984). Gramsci con Bourdieu. Hegemonía, consumo y nuevas formas de organización popular. http://nuso.org/media/articles/ downloads/1156 1.pdf

172 González, J. P. (2001). Musicología popular en América Latina: síntesis de sus logros, problemas y desafios. http://www.scielo.cl/scielo.php?script=sci_art text\&pid=S0716-27902001019500003

Mandoki, K. (2006). Prácticas estéticas e identidades sociales. Prosaica 2. Siglo XXI editores. México

Noguera, A. P. (2000). Educación Estética y Complejidad Ambiental. Universidad Nacional de Colombia. Sede Manizales.

Noguera, A. P. (2004). El Reencantamiento del Mundo. Universidad Nacional de Colombia. Sede Manizales.

Noguera, A. P. (2007). (Compiladora). El paso del sujeto/objeto al bucle redtrama de vida. Disolución de la epistemología moderna y emergencia de la filosofía ambiental. En: Hojas de sol en la victoria Regia. Emergencias de un pensamiento ambiental alternativo en América Latina: Universidad Nacional de Colombia.

Noguera, A. P. (2012). Cuerpo-Tierra: El Enigma, El Habitar, La Vida. Emergencias de un Pensamiento Ambiental en clave del Reencantamiento del Mundo. Editorial Academia Española, Berlín.

Noguera, A. P. (2017). ¿Para qué poetas en tiempos de devastación? El giro estético del pensamiento ambiental Latino-Abyayalense. En Reyes, Rosales y Noguera. (2017). La vida como centro: arte y educación ambiental. Editorial Universitaria, Universidad de Guadalajara, Revista Sembrando Conciencia. Universidad Nacional de Colombia. 
Noguera, A. P. (2018). Pensamiento Ambiental en la era planetaria. Biopoder, bioética y biodiversidad. Una interpretación de los desafíos simbólicobióticos en la aldea global. Universidad Nacional de Colombia.

Pardo, J. L. (1991). Sobre los Espacios pintar, escribir, pensar.

Perniola, M. (2008). Del sentir. Pre-Textos. España

Pineda, J. (2017). Qué inescrutable yace el enigma...En la caída de Ícaro y en el rapto de Perséfone...En Reyes, Rosales y Noguera (2017). La vida como centro: arte y educación ambiental. Editorial Universitaria, Universidad de Guadalajara, Revista Sembrando Conciencia. Universidad Nacional de Colombia. 